\title{
Hemodialysis without Anticoagulation for a Patient with Chronic Disseminated Intravascular Coagulation
}

\author{
Masayuki Yamanouchi $^{a} \quad$ Yoshifumi Ubara $^{\mathrm{a}, \mathrm{b}} \quad$ Koki Mise $^{\mathrm{a}}$ \\ Noriko Hayami ${ }^{a}$ Rikako Hiramatsu ${ }^{a}$ Keiichi Sumida ${ }^{a}$ Tatsuya Suwabe ${ }^{a}$ \\ Eiko Hasegawa $^{a}$ Junichi Hoshino ${ }^{a}$ Naoki Sawa $^{a}$ Fumi Takemoto $^{c}$ \\ Kenmei Takaichi ${ }^{a, b}$ \\ ${ }^{a}$ Nephrology Center and ${ }^{b}$ Okinaka Memorial Institute for Medical Research, Toranomon \\ Hospital, Tokyo, and 'Department of Nephrology, Jichi Medical University, Tochigi, Japan
}

\section{Key Words}

Hemodialysis without anticoagulation - Chronic disseminated intravascular coagulation .

Thoracic aortic aneurysm · Thrombosis

\begin{abstract}
We report a 68-year-old Japanese man with end-stage renal failure requiring hemodialysis and chronic disseminated intravascular coagulation (DIC) related to thrombosis in an aortic aneurysm. He had undergone graft replacement for the dissection of the ascending and descending thoracic aorta in 1990 and 2002, respectively. Computed tomography disclosed an aneurysm with thrombosis in the residual aorta adjacent to the graft anastomosis. DIC was diagnosed based on elevation of serum fibrinogen degradation products while his activated partial thromboplastin time, prothrombin time and fibrinogen level were normal. In 2008, hemodialysis was initiated for end-stage renal failure. Dialysis was performed without administration of an anticoagulant because his activated clotting time (ACT) was prolonged to $150-180 \mathrm{~s}$. Thereafter, stable hemodialysis continued without clotting in the dialysis circuit until 2013. If monitoring of ACT can be done, hemodialysis without anticoagulation may be a therapeutic option in such patients.

(C) 2014 S. Karger AG, Basel
\end{abstract}




\section{Introduction}

Anticoagulation is usually performed to prevent clotting in the hemodialysis circuit during hemodialysis. Heparin is the standard anticoagulant, but it increases the risk of hemorrhage. The heparin dosage is adjusted based on the whole blood clotting time, using a test such as the activated clotting time (ACT) to avoid both bleeding and clotting in the dialyzer. In patients with a high risk of bleeding, heparin must be avoided, and lowmolecular-weight heparin or a synthetic serine protease inhibitor (nafamostat mesylate) is used instead [1].

We encountered a patient with chronic disseminated intravascular coagulation (DIC), related to aortic dissection and end-stage renal failure that required hemodialysis. In this patient, dialysis was initiated without the administration of an anticoagulant because his ACT was prolonged to 150-180 s, and he has since continued dialysis for 3 years without any problems. We also discuss the problems posed by chronic DIC in patients on hemodialysis.

\section{Case Report}

In November 2008, a 68-year-old Japanese man was admitted to our hospital for the construction of an arteriovenous fistula (AVF). Proteinuria and hematuria had been noted at the age of 18 years. Hypertension was diagnosed when he was 40 years old and a calcium channel blocker was prescribed. In 1990, chest pain occurred suddenly without any precipitating cause, and dissection of the ascending thoracic aorta (Stanford A type) was diagnosed. Surgical treatment was performed using a synthetic graft. In 2002, dissection also occurred in the descending thoracic aorta (Stanford B type) and surgical repair was done. Since then, mild thrombocytopenia with a platelet count of around $100,000 / \mathrm{ml}$ had been noted, but he was asymptomatic. Computed tomography (CT) was done every 6 months and revealed a new aneurysm with thrombosis in the residual aorta, adjacent to the anastomosis, in 2005 (fig. 1). No further surgical treatment was performed. In August 2008, an AVF was constructed to allow dialysis for end-stage renal failure, but a transfusion was required (400 $\mathrm{ml}$ of red blood cells and 1,600 $\mathrm{ml}$ of fresh-frozen plasma) because of the massive bleeding. Thereafter, his platelet count decreased to $52,000 / \mu \mathrm{l}$ while his prothrombin time (PT) was 80.5\% (normal: $>75$ ), his activated partial thromboplastin time (APTT) was $31.9 \mathrm{~s}$ (normal range: 27.0-40.0), fibrinogen was $128.4 \mathrm{mg} / \mathrm{dl}$ (normal range: 120-300), fibrinogen degradation products (FDP) were $119.5 \mu \mathrm{g} / \mathrm{ml}$ (normal range: <5), and D-dimer was 79.8 $\mu \mathrm{g} / \mathrm{l}$ (normal range: <1). In addition, the thrombin-antithrombin complex level was 46.4 $\mathrm{ng} / \mathrm{ml}$ (normal range: 3-4), the plasmin- $\alpha_{2}$ plasmin inhibitor complex was $4.9 \mathrm{mg} / \mathrm{ml}$ (normal range: $<0.8$ ), and antithrombin-3 was 69.6\% (normal range: 84-122) (table 1). Chronic DIC, a less active condition than acute DIC, was diagnosed based on the following findings: an underlying disease associated with DIC (aortic aneurysm), elevation of FDP, APTT, PT, and fibrinogen within the normal range and mild thrombocytopenia [2, 3]. CT showed no change of the aortic aneurysm. There was no evidence of other risk factors for chronic DIC, including malignancy. Therefore, his chronic DIC was considered to be secondary to the aortic aneurysm with thrombosis. Initiation of hemodialysis was required in December 2008 due to a urea nitrogen level of $120 \mathrm{mg} / \mathrm{dl}$ and a creatinine level of 7.1 $\mathrm{mg} / \mathrm{dl}$. It was considered that administration of an anticoagulant for dialysis sessions was associated with a high risk of worsening his aortic condition. Therefore, because his ACT was prolonged to 150-180 s (normal range: 90-140), hemodialysis was started without the 
administration of an anticoagulant and was therefore performed successfully without any complications (such as clotting inside the dialysis circuit or dialyzer). Thereafter, hemodialysis ( $4 \mathrm{~h}, 3$ times weekly) was continued without an anticoagulant, and he is doing well as of February 2012.

\section{Discussion}

DIC is primarily due to an uncontrolled and excessive production of thrombin, leading to a widespread intravascular fibrin deposition. The deposition of fibrin results in tissue ischemia and an increased consumption of platelets, fibrinogen, prothrombin, and factors $\mathrm{V}$ and VIII, which, in turn, may lead to bleeding $[4,5]$. DIC is a dynamic process and its consequences depend on both the cause and the rapidity with which the event is propagated. If the reaction is rapid, the clinical picture (acute DIC or decompensated DIC) is dominated by intravascular coagulation. If activation occurs slowly, an excess of procoagulants is produced and this predisposes the patient to thrombosis. At the same time, as long as the liver can compensate for the consumption of clotting factors and the bone marrow maintains an adequate platelet count, the bleeding diathesis will not be clinically apparent. This is known as chronic DIC (compensated DIC) [6]. Chronic DIC is usually associated with carcinomatosis or retained fetus syndrome, but $3-4 \%$ of patients have aortic aneurysms [7, 8]. The incidence of clinically overt DIC is approximately $0.5-1 \%$ among patients with large aortic aneurysms [8]. The treatment involves a correction of the underlying disease and initiating factors in a patient with DIC, so administration of heparin is generally limited to the subset of patients with chronic compensated DIC [9].

Hemodialysis requires blood to flow through an extracorporeal circuit and some form of anticoagulation (usually heparin) is needed to prevent thrombosis in the circuit. Anticoagulation during hemodialysis can be monitored by measuring the ACT, which is maintained at 200-250 s (normal range: 90-140 s). In high-risk patients, it is recommended to keep the ACT in a range from 150 to $200 \mathrm{~s}$ to reduce bleeding complications [10].

In conclusion, we performed hemodialysis without anticoagulation in a patient who had DIC. In this patient, a new aneurysm in the remnant aorta adjacent to the surgical anastomosis might have led to the intravascular deposition of fibrin via local activation of coagulation. Then long-standing consumption of coagulation factors and platelets by this local lesion presumably caused a systemic decrease of these factors and resulted in DIC. Because our patient had an ACT of 150-180 s, hemodialysis was performed for $4 \mathrm{~h}$ per session without anticoagulation and there were no complications such as clotting in the dialyzer. In patients with chronic DIC, performing hemodialysis presents a challenge. However, if monitoring of the ACT can be done, hemodialysis without anticoagulation can be a therapeutic option for such patients.

\section{Acknowledgement}

This study was supported by the Okinaka Memorial Institute for Medical Research.

\section{Disclosure Statement}

All authors report no conflicts of interest. 


\begin{tabular}{l|l}
\hline DOI: 10.1159/000358269 & $\begin{array}{l}\text { ○ 2014 S. Karger AG, Basel } \\
\text { www.karger.com/cru }\end{array}$ \\
\hline
\end{tabular}

Yamanouchi et al.: Hemodialysis without Anticoagulation for a Patient with Chronic Disseminated Intravascular Coagulation

\section{References}

1 Ward DM: Anticoagulation in patients on hemodialysis; in Nissenson AR, Fine RN (eds): Clinical Dialysis, ed 4. New York, McGraw-Hill, 2005, pp 127-152.

2 Taylor FB Jr, Toh CH: Towards definition, clinical and laboratory criteria, and a scoring system for disseminated intravascular coagulation. Thromb Haemost 2001;86:1327-1330.

3 Arruda VR, High KA: Coagulation disorders; in Longo DL, Fauci AS, Kasper DL, Hauser SL, Jameson JL, Loscalzo J (eds): Harrison's Principles of Internal Medicine, ed 18. New York, McGraw-Hill, 2012, pp 973982.

4 Levi M, Ten Cate H: Disseminated intravascular coagulation. N Engl J Med 1999;341:586-592.

5 Levi M: Current understanding of disseminated intravascular coagulation. Br J Haematol 2004;124:567576.

6 Baglin T: Disseminated intravascular coagulation: diagnosis and treatment. BMJ 1996;312:683-687.

7 Fisher DF Jr, Yawn DH, Crawford ES: Preoperative disseminated intravascular coagulation associated with aortic aneurysms. A prospective study of 76 cases. Arch Surg 1983;118:1252-1255.

-8 Aboulafia DM, Aboulafia ED: Aortic aneurysm-induced disseminated intravascular coagulation. Ann Vasc Surg 1996;10:396-405.

-9 Feinstein DI: Diagnosis and management of disseminated intravascular coagulation: the role of heparin therapy. Blood 1982;60:284-287.

-10 Swartz RD, Port FK: Preventing hemorrhage in high-risk hemodialysis: regional versus low-dose heparin. Kidney Int 1979;16:513-518. 
Table 1. Laboratory data after surgery

\begin{tabular}{lll}
\hline Platelet, $\mu \mathrm{l}$ & 52,000 & $(155,000-350,000)$ \\
APTT, s & 31.9 & $(27.0-40.0)$ \\
PT, \% & 80.5 & $(>75 \%)$ \\
PT-INR & 1.15 & \\
Fibrinogen, mg/dl & 128.4 & $(150-300)$ \\
FDP, $\mu \mathrm{g} / \mathrm{ml}$ & 119.5 & $(<5)$ \\
D-dimer, $\mu \mathrm{g} / \mathrm{ml}$ & 79.8 & $(<1)$ \\
AT-III, \% & 69.6 & $(84-122)$ \\
Plasminogen, \% & 34 & $(75-125)$ \\
TAT, ng/ml & 46.4 & $(3-4)$ \\
PIC, $\mu \mathrm{m} / \mathrm{ml}$ & 4.9 & $(<0.8)$ \\
Total PAI-1, ng/ml & $<10$ & $(<50)$ \\
Factor II, \% & 67 & $(75-135)$ \\
Factor V, \% & 67 & $(70-135)$ \\
Factor VII, \% & 79 & $(75-140)$ \\
Factor VIII, \% & 75 & $(60-150)$ \\
Factor IX, \% & 90 & $(70-130)$ \\
Factor X, \% & 74 & $(70-130)$ \\
Factor XI, \% & 57 & $(75-145)$ \\
Factor XII, \% & 85 & $(50-150)$ \\
Factor XIII, \% & 27 & $(70-140)$ \\
Activated vWF, \% & 128 & $(60-170)$ \\
PIVKA-II, $\mu$ g/ml & $<1$ & $(<1)$ \\
Protein C antigen, \% & 62 & $(70-150)$ \\
Activated protein C, \% & 66 & $(64-146)$ \\
Protein S antigen, \% & 73 & $(65-135)$ \\
Activated protein S, \% & 84 & $(60-150)$ \\
\hline
\end{tabular}

Values in parentheses indicate normal range. INR = International normalized ratio; $\mathrm{AT}=$ antithrombin; $\mathrm{TAT}=$ thrombin-antithrombin complex; PIC = plasmin inhibitor complex; $\mathrm{PAI}=$ plasminogen activator inhibitor; $\mathrm{vWF}=$ von Willebrand factor; $\mathrm{PIVKA}=$ protein induced by vitamin $\mathrm{K}$ absence. 
Case Reports in

Nephrology and

Urology

\begin{tabular}{l|l}
\hline Case Rep Nephrol Urol 2014;4:25-30 \\
\hline DOI: 10.1159/000358269 & $\begin{array}{l}\text { ○ 2014 S. Karger AG, Basel } \\
\text { www.karger.com/cru }\end{array}$ \\
\hline
\end{tabular}

Yamanouchi et al.: Hemodialysis without Anticoagulation for a Patient with Chronic Disseminated Intravascular Coagulation

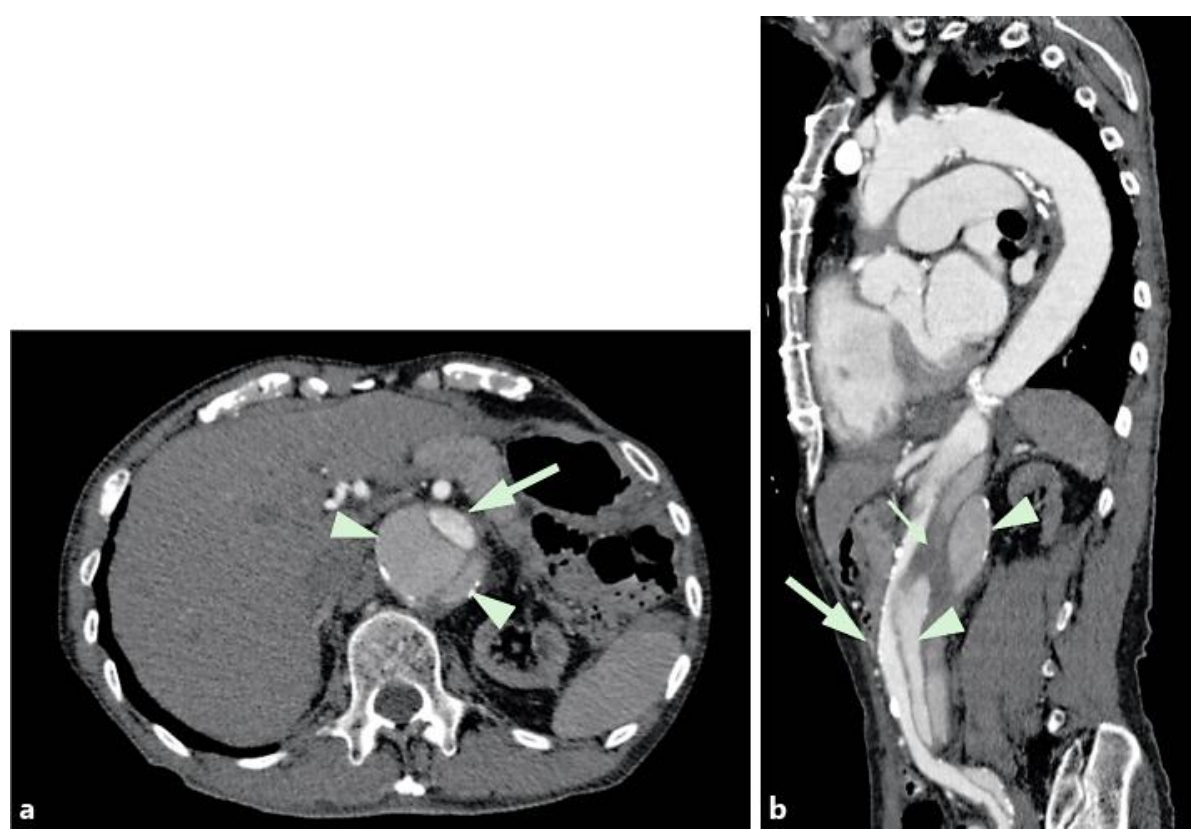

Fig. 1. Enhanced CT shows old thoracic aortic dissection: true lumen (large arrows), thrombosis (small arrow), and pseudolumen (arrowheads). a Axial image. b Sagittal image. 